DOI: http://dx.doi.org/10.25181/esai.v12i2.1109

Jurnal Ilmiah ESAI Volume 12, No. 2, Juli 2018

p-ISSN 1978-6034 e-ISSN 2580-4944

Analysis of the Altman Z-Score Bankruptcy Prediction Model. Springate and Zmijewski to Assess the Business Continuity of PT Enseval Putera Megatrading Tbk

\title{
Analisis Model Prediksi Kebangkrutan Altman Z-Score. Springate dan Zmijewski untuk Menilai Kelangsungan Usaha PT Enseval Putera Megatrading Tbk
}

\author{
Choirunnisa Nurahayu ${ }^{1)}$, Evi Yuniarti ${ }^{2)}$, Nurmala ${ }^{3)}$ \\ 1) Program Studi Akuntansi Jurusan Ekonomi Dan Bisnis Politeknik Negeri Lampung \\ 2) Staf Pengajar pada Program Studi Akuntansi Jurusan Ekonomi Dan Bisnis Politeknik Negeri \\ Lampung \\ 3) Staf Pengajar pada Program Studi Akuntansi Perpajakan Jurusan Ekonomi Dan Bisnis \\ Politeknik Negeri Lampung
}

\begin{abstract}
The economic development of PT EPM Tbk in 2011 to 2016 did not improved, because in 2011 to 2016 the cash flow statement of PT EPM Tbk. decreased. This writing aims to determine the prediction of bankruptcy at PT EPM Tbk with the Altman Z-Score, Springate and Zmijewski Score models to assess the business continuity of PT EPM Tbk from 2011 to 2016. The analysis technique used is the Altman Z-Score bankruptcy prediction model, Springate and the Zmijewski Score for various types of companies. Based on the results of the analysis of the three bankruptcy prediction models Altman Z-Score, Springate Score and Zmijewski Score shows that the business continuity assessment of PT Enseval Putera Megatrading Tbk in 2011 to 2016 is a company in good financial condition or a healthy company and is not at risk The Z-Score is more than the Altman Z-Score, Springate Score and Zmijewski Score standards.
\end{abstract}

Keywords: Altman Z-Score, Springate Score, Zmijewski Score and Business Continuity

\section{Pendahuluan}

Secara umum, kebangkrutan merupakan kegagalan atau kesalahan perusahaan dalam menjalankan usaha untuk mencapai tujuannya. Kebangkrutan tidak terjadi secara tiba-tiba. Kebangkrutan adalah akumulasi dari kesalahan pengelolaan perusahaan dalam jangka panjang. Karena itu, diperlukan alat untuk mendeteksi potensi kebangkrutan yang mungkin dialami perusahaan. Analisis prediksi kebangkrutan diperlukan untuk memperoleh peringatan awal kebangkrutan. Analisis prediksi kebangkrutan merupakan salah satu cara yang dapat digunakan untuk memprediksi kebangkrutan agar pihak manajemen perusahaan dapat melakukan antisipasi yang diperlukan dari peringatan awal kebangkrutan. Perkembangan ekonomi PT EPM Tbk pada tahun 2011 sampai dengan 2016 kurang membaik, karena pada tahun 2011 sampai dengan 2016 laporan arus kas PT EPM Tbk mengalami penurunan. Laporan arus kas tersebut dapat dilihat pada tabel 1 sebagai berikut. 
Tabel 1. Arus Kas PT Enseval Putera Megatrading Tbk tahun 2011-2016

\begin{tabular}{|c|c|c|}
\hline Keterangan & Jumlah (Rp) & Tahun \\
\hline \multirow[t]{6}{*}{ Kas Neto Diperoleh dari (Digunakan Untuk) Aktivitas Operasi } & 392.910 .207 .057 & 2011 \\
\hline & 359.080 .766 .092 & 2012 \\
\hline & (153.301.485.087) & 2013 \\
\hline & 520.135 .657 .562 & 2014 \\
\hline & 614.574 .249 .011 & 2015 \\
\hline & 244.821 .541 .649 & 2016 \\
\hline \multirow[t]{6}{*}{ Kas Neto Digunakan Untuk Aktivitas Investasi } & $(156.322 .245 .648)$ & 2011 \\
\hline & $(85.464 .977 .730)$ & 2012 \\
\hline & $(258.482 .529 .263)$ & 2013 \\
\hline & (183.193.002.268) & 2014 \\
\hline & (196.790.677.629) & 2015 \\
\hline & $(31.740 .666 .460)$ & 2016 \\
\hline \multirow[t]{6}{*}{ Kas Neto Diperoleh dari (Digunakan untuk) Aktivitas Pendanaan } & 286.733 .158 .548 & 2011 \\
\hline & (235.071.451.726) & 2012 \\
\hline & $(1.370 .330 .331)$ & 2013 \\
\hline & (40.485.189.890) & 2014 \\
\hline & $(27.698 .454 .649)$ & 2015 \\
\hline & $(114.106 .560 .065)$ & 2016 \\
\hline \multirow[t]{6}{*}{ Kas dan Setara Kas Akhir Tahun } & 759.028 .375 .768 & 2011 \\
\hline & 798.816 .291 .756 & 2012 \\
\hline & 388.326 .811 .003 & 2013 \\
\hline & 684.213 .722 .301 & 2014 \\
\hline & 1.077.235.561.992 & 2015 \\
\hline & 1.175 .527 .427 .556 & 2016 \\
\hline
\end{tabular}

Sumber: Laporan Keuangan PT EPM Tbk tahun 2011-2016 diakses melalui www.idx.co.id (data diolah, 2017)

Berdasarkan tabel 1 menunjukkan bahwa arus kas PT EPM Tbk tahun 2011-2016 mengalami penurunan. Kas neto diperoleh dari (digunakan untuk) aktivitas operasi PT EPM Tbk pada tahun 2013 mengalami penurunan yang signifikan, penurunan kas terjadi karena meningkatnya pembayaran untuk pemasok, karyawan dan pajak penghasilan. Kas neto digunakan untuk aktivitas investasi pada tahun 2016 mengalami penurunan yang signifikan, penurunan kas terjadi karena menurunnya penempatan pada investasi tersedia untuk dijual. Kas Neto Diperoleh dari (Digunakan untuk) Aktivitas Pendanaan pada tahun 2013 mengalami penurunan, penurunan kas terjadi karena penurunan pembayaran deviden kas kepada para pemegang saham. Kas dan Setara Kas Akhir Tahun pada tahun 2013 mengalami penurunan yang signifikan, penurunan terjadi karena menurunnya kas dan setara kas (per laporan posisi keuangan konsolidasian). Berdasarkan data tersebut, kondisi arus kas PT EPM Tbk selama tahun 2011 sampai dengan 2016 menunjukkan adanya penurunan kas dan setara kas. Permasalahan penurunan arus kas yang terjadi akan berdampak pada kemungkinan perusahaan mengalami kebangkrutan yang berarti kegagalan perusahaan menjalankan operasi perusahaan. 
DOI: http://dx.doi.org/10.25181/esai.v12i2.1109

Banyak model yang telah dikembangkan oleh para peneliti terdahulu untuk memprediksi kebangkrutan. Dari beberapa model yang telah dikembangkan tersebut, penulis disini akan menggunakan tiga model yaitu: Altman Z-score, Springate dan Zmijewski dalam (Rudianto, 2013). Modelmodel ini dipilih karena dalam proses penerapannya mudah untuk diterapkan dan mudah untuk dipahami serta memiliki tingkat keakuratan yang cukup tinggi dalam melakukan prediksi potensi kebangkrutan suatu perusahaan.

Seperti penelitian yang telah dilakukan oleh Yulistary dan Wirakusuma (2014) yang berjudul analisis financial distress dengan metode Z-Score Altman, Springate, dan Zmijewski pada perusahaan PT Fast Food Indonesia Tbk yang terdaftar di Bursa Efek Indonesia (BEI) periode tahun 2008-2012. Dijelaskan bahwa hasil analisis PT Fast Food Indonesia Tbk dengan menggunakan metode analisis Z-Score Altman, Springate, dan Zmijewski tahun 2008 sampai dengan 2012 perusahaan diklasifikasikan dalam keadaan sehat. Analisis model prediksi kebangkrutan Altman Z-Score, Springate dan Zmijewski Score dalam (Rudianto, 2013) digunakan dalam menganalisis laporan keuangan PT EPM Tbk agar dapat melihat tanda-tanda kebangkrutan yang kemungkinan akan terjadi dan untuk menilai kelangsungan usaha perusahaan apakah kinerja keuangan PT EPM Tbk selama tahun 2011 sampai dengan 2016 tergolong perusahaan sehat, rawan bangkrut atau berpotensial bangkrut.

Metode Pelaksanaan
Alat dan bahan yang digunakan dalam penulisan laporan tugas akhir ini berupa laporan keuangan PT Enseval Putera Megatrading Tbk tahun 2011-2016 yang berupa laporan posisi keuangan, laporan laba rugi serta laporan perubahan ekuitas yang diperoleh dari Bursa Efek Indonesia. Jenis data yang digunakan dalam penulisan laporan tugas akhir ini adalah data sekunder. Metode analisis data yang digunakan penulis dalam laporan tugas akhir ini adalah metode deskriptif kuantitatif.

Alat analisis kuantitatif dalam (Rudianto, 2013) ini meliputi:

\section{Altman Z-Score untuk berbagai jenis perusahaan

$$
Z=6,56 X_{1}+3,26 X_{2}+6,72 X_{3}+1,05 X_{4}
$$

Keterangan:

$\mathrm{X}_{1}=$ Modal kerja terhadap total harta (Working Capital to Total Asset)

$\mathrm{X}_{2}=$ Laba ditahan terhadap total harta (Retained Earning to Total Asset)

$\mathrm{X}_{3}=$ Laba sebelum bunga dan pajak terhadap total harta (Earning Before Interest and Tax to Total Asset)

$\mathrm{X}_{4}=$ Nilai buku ekuitas terhadap nilai buku utang (The book value of equity to the book value of debt)

\section{Springate Score}

$$
Z=1,03 X_{1}+3,07 X_{2}+0,66 X_{3}+0,4 X_{4}
$$

Keterangan:

$\mathrm{X}_{1}=$ Modal kerja terhadap total harta (Working Capital to Total Asset)

$\mathrm{X}_{2}=$ Laba sebelum bunga dan pajak terhadap total harta (Earning Before Interest and Tax to Total Asset) 
DOI: http://dx.doi.org/10.25181/esai.v12i2.1109

$\mathrm{X}_{3}=$ Laba sebelum pajak terhadap utang lancar (Earning Before Tax to Current Liabilities)

$\mathrm{X}_{4}=$ Penjualan terhadap total harta (Sales to Total Asset)

\section{Zmijewski Score}

$$
Z=-4,3-4,5 X_{1}+5,7 X_{2}-0,004 X_{3}
$$

Keterangan:

$\mathrm{X}_{1}=$ Laba bersih terhadap total harta (Net Profit to Total Asset)

$\mathrm{X}_{2}=$ Total utang terhadap total harta (Total Debt to Total Asset)

Tabel 2. Hasil Analisis Ketiga Model Prediksi Kebangkrutan

\begin{tabular}{lccc}
\hline Model Prediksi Kebangkrutan & Tahun & Hasil Analisis & Zona Perusahaan \\
\hline Altman Z-Score & 2011 & 6,331 & Zona Aman \\
& 2012 & 5,806 & Zona Aman \\
& 2013 & 6,115 & Zona Aman \\
& 2014 & 6,496 & Zona Aman \\
& 2015 & 7,069 & Zona Aman \\
Springate Score & 2016 & 7,941 & Zona Aman \\
& 2011 & 1,896 & Zona Aman \\
& 2012 & 1,962 & Zona Aman \\
& 2013 & 2,042 & Zona Aman \\
& 2014 & 2,038 & Zona Aman \\
& 2015 & 2,034 & Zona Aman \\
& 2016 & 2,136 & Zona Aman \\
\hline Zmijewski Score & 2011 & $-2,148$ & Zona Aman \\
& 2012 & $-1,941$ & Zona Aman \\
& 2013 & $-2,119$ & Zona Aman \\
& 2014 & $-2,248$ & Zona Aman \\
& 2015 & $-2,416$ & Zona Aman \\
& 2016 & $-2,683$ & Zona Aman \\
\hline
\end{tabular}

Sumber: Laporan Keuangan PT EMP Tbk Tahun 2011-2016 (data diolah)

Berdasarkan tabel 2 dapat kita lihat bahwa hasil analisis model Altman Z-Score pada tahun 2011 sampai dengan 2016 PT EPM Tbk dalam zona aman dengan nilai $Z$ Score 6,331, 5,806, 6,115, 6,496, 7,069 dan
$\mathrm{X}_{3}=$ Aset lancar terhadap utang lancar (Current Asset to Current Liabilities)

\section{Hasil Dan Pembahasan}

Setelah melakukan perhitungan terhadap ketiga model prediksi kebangkrutan kemudian hasil nya akan diinterpretasikan kedalam nilai Z-score untuk menentukan zona perusahaan. Berikut ini adalah pengelompokan zona perusahaan terhadap ketiga model prediksi kebangkrutan: 
dengan 2016 mengalami kondisi yang sangat baik, dan tidak beresiko terhadap kebangkrutan jika perusahaan tetap berada di pihak manajemen yang kompeten yang dapat mengatasi faktor-faktor penyebab kebangkrutan.

Hasil analisis model Springate Score pada tahun 2011 sampai dengan 2016 PT EPM Tbk dalam zona aman dengan nilai Z-Score 1,896, 1,962, 2,042, 2,038, 2,034 dan 2,136 yang nilai $Z$-Score nya lebih dari 0,862 yang artinya perusahan dalam kondisi keuangan yang baik. Berdasarkan teori Springate Score mengenai kebangkrutan perusahaan, maka PT EPM Tbk pada tahun 2011 sampai dengan 2016 mengalami kondisi yang sangat baik, dan tidak beresiko terhadap kebangkrutan jika perusahaan tetap berada di pihak manajemen

\section{Kesimpulan}

Berdasarkan teori dan hasil analisis ketiga model prediksi kebangkrutan maka dapat disimpulkan bahwa penilaian kelangsungan usaha PT Enseval Putera Megatrading Tbk tahun 2011 sampai dengan 2016 adalah perusahaan dalam kondisi keuangan yang baik atau perusahaan sehat dan tidak beresiko terhadap kebangkrutan jika perusahaan tetap berada di pihak manajemen yang kompeten yang dapat mengatasi faktorfaktor penyebab kebangkrutan. yang kompeten yang dapat mengatasi faktorfaktor penyebab kebangkrutan.

Hasil analisis model Zmijewski Score pada tahun 2011 sampai dengan 2016 PT EPM Tbk dalam zona aman dengan nilai $Z$ Score -2,148, -1,941, -2,119, -2,248, -2,416 dan $-2,683$ yang nilai $Z$-Score nya bernilai negatif yang artinya perusahan dalam kondisi keuangan yang baik. Berdasarkan teori Zmijewski Score mengenai kebangkrutan perusahaan, maka PT EPM Tbk pada tahun 2011 sampai dengan 2016 mengalami kondisi yang sangat baik, dan tidak beresiko terhadap kebangkrutan jika perusahaan tetap berada di pihak manajemen yang kompeten yang dapat mengatasi faktor-faktor penyebab kebangkrutan.

\section{Daftar Pustaka}

Bursa Efek Indonesia. 2017. Perusahaan Tercatat: Laporan Keuangan dan Tahunan. http://www.idx.co.id. Jakarta. [Diunduh pada tanggal 11 April 2017].

Rudianto. 2013. Akuntansi Manajemen Informasi untuk Pengambilan Keputusan Strategis. Erlangga. Jakarta.

Yuliastary, Etta Citrawati dan Made Gede Wirakusuma. 2014. Analisis Financial Distress dengan metode Altman ZScore, Springate, Zmijewski. E-Jurnal Akuntansi Universitas Udayana, Vol. 6, No. 3.

Yuniarti, Evi dan Fadila Margasatya. 2007. Pengaruh Locus of Control \& Kultur Organisasional Terhadap Keefektifan Anggaran Parsipatif Dalam Peningkatan Kinerja Manajeril. Jurnal Manajemen Akuntansi dan Bisnis. Vol. 5 No.2 Tahun 2007. 